\title{
Lina Bo Bardi y espaciamientos urbanos
}

\author{
Nathalia Giovannini Botelho*
}

\section{Resumen}

A partir del pensamiento desarrollado por Marc Augé y el concepto de no lugares, se analizan las estrategias utilizadas por la arquitecta Lina Bo Bardi para que los posibles no lugares en sus proyectos se conviertan en poderosos espacios públicos urbanos (entendidos como intervalos, como el entre) y, por lo tanto, espaciamiento urbano y no espacio urbano. Así, a través del abordaje de estos conceptos, además, se abordan dos proyectos de la arquitecta: el vano del Museo de Arte de San Pablo (MASP) y los corredores externos del Centro Cultural Servicio Social del Comercio (SEsC) de Pompéia.

Palabras clave: espacio público, espacios urbanos, habitar

\section{Abstract}

Based on the thinking developed by Marc Augé and the concept of non-places, the strategies used by the architect Lina Bo Bardi are analyzed so that the possible non-places in their projects become powerful urban public spaces (understood as intervals, such as between) and, therefore, urban spacing and not urban space. Thus, through the approach of these concepts, in addition, two projects of the architect are addressed: the opening of the Art Museum of São Paulo (MASP) and the external corridors of the Pompeia's Cultural Center SESC.

Keywords: inhabit, public space, urban spaces

\footnotetext{
* Estudiante de Maestría en Artes Visuales de la Universidad Federal de Rio de Janeiro, graduada de Arquitectura y Urbanismo de la Universidad Santa Úrsula y Bacharela. Summa cum laude en Historia del Arte de la Escuela de Bellas Artes, Universidad Federal de Rio de Janeiro. Participante de la oficina Tercera Margen - Arquitectura y singularidades. Integrante del Colectivo a PÉ (C_APÉ). Contacto: gior.nathalia@gmail.com
} 
There is no such thing as an empty space or an empty time. There is always something to see, something to hear. In fact, try as we may to make a silence, we cannot.

JoHn CAGE, Silence

Achilina de Enrico Bo, conocida como Lina Bo Bardi, nació en Roma en 1914 y murió en San Pablo en 1992. Graduada de la Facultad de Arquitectura de Roma en 1940, vio de cerca el poder destructivo del fascismo y de la consecuente Segunda Guerra Mundial. Se mudó a Brasil en 1946 y fijó su residencia en San Pablo, allí tuvo una actuación diversa e intensa. Al margen de lo que estaba siendo políticamente constituido en el país y alimentada por los ideales de Antonio Gramsci ${ }^{1}$, tejía otras estrategias para fomentar una civilización genuinamente moderna en Brasil, a través de la unificación del pensamiento moderno y de la cultura popular.

Salvaguardar al máximo las fuerzas genuinas del país, buscando al mismo tiempo estar al corriente del desarrollo internacional, será la base de la nueva acción cultural, buscando, sobre todo, no disminuir o elementarizar los problemas, presentándolos al pueblo como un alimento soso y desvitalizado; no eliminar un lenguaje que es especializado y difícil pero que existe, interpretar y evaluar esa corriente; y sobre todo será útil recordar las palabras de un filósofo de la praxis 'No se curvan al hablar con las masas, señores intelectuales, enderezar la espalda'. (Rubino y Grinover, 2009, p. 45)
Hoy, Lina Bo Bardi es considerada fundamental para comprender el pensamiento arquitectónico en Brasil y también el ideal utópico de nación moderna. Por ello, en este escrito se abordan, especialmente, dos proyectos de la arquitecta: el Museo de Arte de San Pablo (MASP) y el Centro Cultural Servicio Social del Comercio (SESC) de Pompéia, los dos localizados en San Pablo (ciudad más poblada y también poseedora del mayor PIB de Brasil); de hecho, el centro económico brasileño. Fundada en 1554, hoy San Pablo es un ejemplo de las grandes metrópolis mundiales: polifacética, densa y compleja en sus relaciones y disputas de renta, oportunidades y territorios.

Las dos obras elegidas corresponden a lugares proyectados para el pueblo, no solo arquitectónicamente, sino también en cuanto a la intención de reflejar la educación y la formación cultural de la base trabajadora de la ciudad. En las obras de Bo Bardi, la visualidad formal no es el punto de partida, sino vivencia de los espacios. Esta vivencia pasa por el afecto que estos lugares provocan en quien pasa por ellos: al percibirlos nos damos cuenta de la necesidad latente de espaciamientos como resistencia a la ocupación, resistencia a la producción intermitente impuesta por el ritmo de una gran metrópoli industrial.

\footnotetext{
1 Filósofo italiano (1891-1937); como miembro activo del Partido Comunista de Italia fue arrestado en 1926 por promotores fascistas. Escribió mientras estuvo preso una obra extensa que fue, póstumamente, publicada como Quaderni del carcere (Cuadernos de la cárcel). En estos cuadernos reflexiona sobre conceptos humanistas fundamentales tales como hegemonía cultural, civilización, revolución pasiva, filosofía de la praxis y otros. Así, fundamenta otro pensamiento histórico-socialista que actualizaría cuestiones marxistas. El pensamiento gramsciano tuvo un profundo impacto en los intelectuales, sobre todo en los italianos, incluyendo a Lina Bo Bardi. Para ella, era clara la cuestión gramsciana de la integración de la base popular a la fuerza intelectual para la construcción de una sociedad civil unificada y moderna.
} 
Los espaciamientos provocan detenerse, invitan a estar y habitar. Aquí los defendemos como lugares de intervalo que rompen la lógica instaurada en su entorno. Lugares pasivopotentes en medio de la actividad de los centros urbanos que no se someten a la lógica funcionalista racionalista de los arquitectos transformistas, pero que tampoco ceden a la ideología de la ciudad genérica hoy defendida por Rem Koolhaas. Estos intervalos son vacíos que reclaman el habitar; lugares vacíos, pues no emplean un programa específico, mas expresan identidad y por eso suscitan relaciones con los cuerpos que se ponen a disposición al habitar.

Bo Bardi no proyecta esos espaciamientos para la fruición clásica de la arquitectura. Lo que interesa de esos lugares no es la pura apreciación formal, la distribución de los volúmenes en el espacio, la simetría monumental y la satisfacción de la mirada de aquellos que los observan. No basta mirar y admirar, es preciso relacionarse con ellos, pues no se proponen ser el comienzo ni el fin, sino un entre en el que se permite la experimentación, la proposición de otras actividades. El entre responde a los cuerpos potenciando la experiencia de esas iniciativas. A continuación, se analizan los dos casos, presentados como afirmación de espaciamientos urbanos de uso colectivo y no espacio (genérico) público.

El MASP fue proyectado en 1957 e inaugurado en 1968. Situado en la importante Avenida Paulista, es uno de los principales museos de América Latina. Con acervo diverso, de más de diez mil obras entre pinturas, esculturas, objetos, fotografías, videos y otros, posee importantes representantes de la producción europea, africana, asiática y americana. Bo Bardi proyecta un complejo arquitectónico que alberga biblioteca, teatro-auditorio, salas de exposiciones temporales, pinacoteca, tienda $\mathrm{y}$ restaurante. Además, y para lo que aquí nos interesa, donde antes se tenía un belvedere, ahora se tiene el proyecto de un vacío, constituido por un vano libre de casi 80 metros de largo con pie derecho de 8 metros y una plaza. Bo Bardi, al mantener esa apertura, rescata y mantiene una vitalidad histórica, no hay el interés de enterrar lo que allí fue vivido, cada capa histórica tiene su importancia. Necesitamos reconocerlas y actualizarlas, es lo que esta arquitecta hace en el MASP. El rescate no es hecho por la reconstrucción literal de un mirador bucólico del paisaje, sino por un vacío enmarcado, imponentemente, por su estructura en rojo. Un intervalo de la ciudad guardado para el pueblo.

En medio del caos de la intensa producción capitalista, ostentada por la verticalidad de los rascacielos de la Avenida Paulista, un vacío señala la necesidad de la improductividad. Un espaciamiento, un lugar para la relación entre tiempo, sujeto y ciudad. Un lugar donde la ciudad se hace sujeto y el sujeto se hace ciudad, un espacio de creación colectiva. Allí, los juicios están suspendidos y hay libertad para el habitar de los cuerpos.

De la acera somos atraídos por la posibilidad de ver la ciudad, ese intervalo invita al atravesar. Al caminar por el espaciamiento, nos sentimos animados a ir de encuentro con el otro (el sujeto-ciudad). Durante la caminata cruzamos con otros cuerpos que actúan allí como agentes no programados, libres. El vano del MASP fue pensado para ser un lugar que existe con ocupaciones, un ambiente pasivo-potente que provoca a los cuerpos a adentrarlo para develar y experimentar la libertad que allí se presenta. Un espacio que guarda la posibilidad de la sorpresa y de lo inesperado en la ciudad. 
En este análisis se establecen comparaciones entre el vano del MASP y los corredores de circulación del Centro Cultural SESC de Pompéia. En esta lógica, es necesario aclarar que el SESC es una institución brasileña mantenida por una asociación de empresarios, pero sus actividades son abiertas al público en general. Existen diversas unidades del SESC por Brasil y sus programaciones están dirigidas a la educación, el ocio, la cultura, la asistencia y la salud.

El Centro Cultural SESC de Pompéia fue proyectado por Lina Bo Bardi en 1977 y abierto al público en 1982. El sitio escogido alberga una antigua fábrica de tambores, donde ella decide mantener la arquitectura existente, de carácter inglés industrial. Los grandes galpones fueron adaptados para alojar un teatro, un restaurante, un espacio expositivo y otras salas administrativas. En el marco del proyecto, Bo Bardi propone un río que corre por el conjunto, un complejo deportivo con agujeros en lugar de las tradicionales ventanas rectangulares y una torre para caja de agua. A partir del deseo de construir una realidad distinta, el Centro Cultural SESC de Pompéia fue creado para proporcionar al pueblo una "pequeña alegría en una triste ciudad" (SESC de Pompeia, 2013, p. 3)

Los corredores son, de acuerdo con Marc Augé2 (2012), no-lugares. Un no-lugar es un espacio de paso, impersonal y desconectado del tiempo, del sujeto-ciudad y que intenta ser neutro. Pero lo que se observa en el Centro Cultural SESC de Pompéia son pasillos como lugares y como espaciamientos: intervalos entre cada uno de los galpones y complejos, lugares en los que, al igual que el vano del MASP, invitan a los cuerpos para que los habiten y se integren sujetos y ciudad.
La pregunta es, ¿cómo transformar un espacio de paso en lugar de estar? No basta simplemente nombrar -como mucho hemos visto, los espacio kids, espacio gourmet, espacio coworking-; no basta con colocar un objeto, tenemos varios bancos esparcidos por la ciudad y, sin embargo, son espacios en los que nadie se queda. Entonces, ¿cómo proyecta Bo Bardi un pasillo como lugar?

Un lugar (espaciamiento) es capaz de comunicarse con los cuerpos, expresar individualidad y transmitir que su existencia es valiosa para el sujeto y para la ciudad. Experimentamos en estos corredores estrategias similares del proyecto para el vano del MASP. El espaciamiento respeta a los sujetos, pues no se impone a los cuerpos, los acoge; es honesto en el empleo de la materialidad, en la simplicidad formal y en la presentificación de las capas históricas.

Al caminar hacia el SESC, aún en la calle, las piedritas en la calzada nos conducen a la puerta de entrada, como indicios de que allí hay un lugar que se propone interrumpir el ritmo urbano usual. La entrada del corredor central es enmarcada por la puerta de madera y postes rojos, lo que indica que allí se abre otra posibilidad de habitar la ciudad. El corredor provoca el cuerpo, provoca los demás sentidos más allá de la mirada. Texturas en el piso y en las paredes, el ruido del agua, el olor de las plantas. El sujeto anestesiado por la rutina se despierta, se pone en disponibilidad para relacionarse con el otro. Símbolos del vocabulario común brasileño comunican que este lugar está abierto al sujeto para que experimente sus propuestas.

Este corredor de entrada no impone un camino, pero despierta al cuerpo a recorrerlo, a la 
velocidad que juzgue necesaria, para disfrutar el propio camino. Corredor como el entre que acoge y prepara los cuerpos para las actividades, que pueden suceder en los galpones, pero también en los propios corredores.

El otro corredor, como lugar de ir, venir y quedarse, está ubicado en el fondo del terreno y se superpone a una galería de aguas pluviales (corriente de aguas negras). Bo Bardi proyecta una pasarela de madera, un deck largo coronado con una ducha al aire libre, una cascada. Delicada y poética, la idea de disponer agua para el uso libre de los visitantes, principalmente cuando se sabe que debajo de los pies corre un río, provoca habitar el espacio. San Pablo es una ciudad de clima seco cuando se compara a otras ciudades de Brasil, no es costera. Allí, si lo desea, el sujeto puede disfrutar del placer de bañarse. En caso de que no se quiera, ese lugar es capaz de albergar otros deseos, los niños pueden jugar o correr, los ancianos descansar, cualquiera tiene la posibilidad de proponer una actividad. Todos pueden, en el colectivo, porque allí, juntos, son despertados para el espaciamiento, una suspensión temporal de las actividades y cuerpos automatizados. Los que habitan estos corredores modifican temporalmente los significados de aquel lugar. La dinámica de la relación tiempo, sujeto y ciudad puede ser experimentada con libertad $\mathrm{y}$, aunque después cada uno vuelva a su dinámica original, se han afectado y esa experiencia resistirá, al menos, en memoria. Estas arquitecturas de espaciamientos invitan a establecer con ellas una experiencia creativa y potente de habitar la ciudad.

A diferencia del vacío, que absorbe todas las acciones y se mantiene inerte a lo que en él sucede, un espaciamiento entabla otras relaciones con el territorio, ofrece lugar para el afecto entre sujetosujeto y sujeto-ciudad. Así, el vano del MAsP y los corredores del Centro Cultural sesc de Pompéia son lugares potentes y abiertos al habitar, espacios que sugieren y contribuyen con otras, muchas otras, posibilidades para vivir la ciudad de San Pablo.

Bo Bardi propone lugares que puedan acoger los cuerpos diversos de una metrópoli plural y pulsante como San Pablo. Los espaciamientos son lugares de libertad, respiro a la aburrida opresión, reforzada por la pasteurización genérica de la arquitectura. Los espaciamientos aproximan y conectan la diversidad, desaceleran los cuerpos y permiten el placer del estar. 


\section{Referencias}

Augé, M. (2012). Não lugares: Introdução a uma antropologia da supermodernidade. Campinas, Brasil: Papirus.

Cage, J. (1973). Silence. Middletown, Estados Unidos: Wesleyan University Press.

Rubino, S. y Grinover, M. (2009). Lina por escrito. Textos escolhidos de Lina Bo Bardi. San Pablo: Cosac Naify.

SESC de Pompeia. (2013). Historia folleto [recurso en línea]. Recuperado de https://bit.

ly/2GF8oAZ 